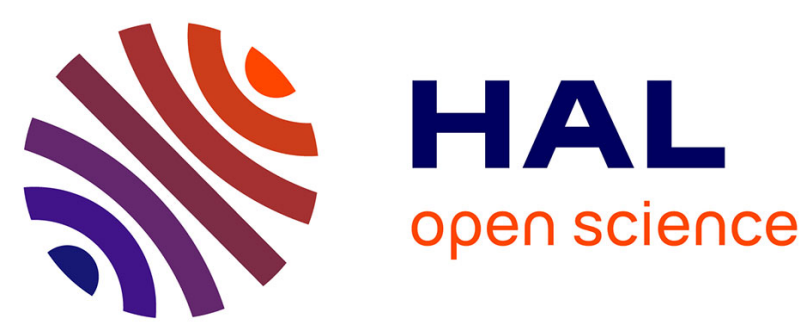

\title{
CHEMICAL VAPOR DEPOSITION OF COPPER FOR MICROELECTRONIC DEVICES BASED ON SILICON
}

\author{
H. Dallaporta, Z. Hammadi, R. Pierrisnard, A. Cros
}

\section{> To cite this version:}

H. Dallaporta, Z. Hammadi, R. Pierrisnard, A. Cros. CHEMICAL VAPOR DEPOSITION OF COPPER FOR MICROELECTRONIC DEVICES BASED ON SILICON. Journal de Physique IV Proceedings, 1991, 02 (C2), pp.C2-889-C2-895. 10.1051/jp4:19912106 . jpa-00249784

HAL Id: jpa-00249784

https://hal.science/jpa-00249784

Submitted on 1 Jan 1991

HAL is a multi-disciplinary open access archive for the deposit and dissemination of scientific research documents, whether they are published or not. The documents may come from teaching and research institutions in France or abroad, or from public or private research centers.
L'archive ouverte pluridisciplinaire HAL, est destinée au dépôt et à la diffusion de documents scientifiques de niveau recherche, publiés ou non, émanant des établissements d'enseignement et de recherche français ou étrangers, des laboratoires publics ou privés. 
Colloque C2, supp1. au Journal de Physique II, Vo1 1, septembre 1991

\title{
CHEMICAL VAPOR DEPOSITION OF COPPER FOR MICROELECTRONIC DEVICES BASED ON SILICON
}

\author{
H. DALLAPORTA, Z. HAMMADI, R. PIERRISNARD and.A. CROS \\ GPEC, URA-CNRS 783, Faculté des Sciences de Luminy, Case \\ 901, F-13288 Marseille cedex 9, France
}

\begin{abstract}
In this paper we present a study of copper CVD deposition on different types of substrates used for microelectronic devices. The influence of substrate temperature, pressure, flux and contamination effect of the gas phase has been determined to obtain the deposition conditions of the metallic films on substrate as clean Si and CrN. Copper acetylacetonate has been used as precursor. The CVD reactor is coupled to an ultra high vacuum chamber with Auger electrons spectroscopy which allows in situ surface characterizations. The chemical composition of the film has been measured for different deposition conditions. These surface techniques have been used with $\mathrm{X}$-ray diffraction to characterize the deposited layers. In the case of silicon substrate the deposited film can either be a pure metal or a metal rich silicide near $\mathrm{Cu}_{4} \mathrm{Si}$ at low or high substrate temperatures respectively. The formation of the copper silicide is compared to the case of $\mathrm{Si} / \mathrm{Cu}$ junctions where the $\mathrm{Cu}$ layer is deposited by electron gun evaporation. Selectivity phenomena have also been observed: Cu growth rate is higher on metallic $\mathrm{CrN}$ substrate than on PPQ insulator.
\end{abstract}

\section{1) Introduction:}

Copper is the material that could replace Aluminum for interconnexion in ULSI technology. Numerous papers has been published on Cu CVD processes during these last few years, most of them are in the superconductor field and few on the metallization for microelectronic (ref.1-8). Open questions still remain that need to be solved for applications in device fabrication. The selectivity and the conformal deposition (ref.9-14) could lead to a drop of device fabrication cost. CVD reactions are very complex and the steps of deposition mechanism are not well known. Systematic studies of the influence of the process conditions on film quality and on the growth rate versus the chemical properties of the substrate can be helpful for a better understanding of the CVD deposition mechanisms. The characteristics of the initial surface play an important role in the formation of the first layers, and must be taken into account to have a better understanding of the selectivity. The originality of our approach comes from the capability of performing a chemical characterization before and after in situ deposition. In this study we have used the copper acetylacetonate which is known to decompose at quite low temperature $\left(300^{\circ} \mathrm{C}\right)$ and provide a metallic copper film. We will focus on the results obtained on $\mathrm{Si}(111)$ where, depending on the process, different compositions can be reached and we will present a case where the selectivity is observed. 


\section{2) Experimental set up:}

This work has been performed in the experimental set up schematically represented in figure 1. The two stainless steel chambers have been designed so that a grown film in the reactor can be transferred to the analysis chamber for surface characterization. The one inch wafer is loaded on a copper heater station, the thermal contact is obtained by spring clips. In this chamber the temperature of the sample can be monitored between the ambient and $500^{\circ} \mathrm{C}$ by a controller allowing different rampings and annealing times. The reproducibility of the sample temperature checked by an infrared pyrometer is better than $5^{\circ} \mathrm{C}$. The temperature of the wall $\left(T_{W}\right)$ and of the container $\left(T_{C}\right)$ are measured by a

thermocouple but not regulated. In the reactor, the base pressure in the $10^{-5} \mathrm{~Pa}$ range is obtained by a turbo pump associated to a stable chemical roughing pump. The pressure in the reactor is measured by an ion gauge from $10^{-7}$ to $0.1 \mathrm{~Pa}$ range and by a thermocouple gauge in the 0.1 to $10 \mathrm{~Pa}$ range: to get the desired pressure in the reactor the pumping speed is limited by adjusting the gate valve between the reactor and the turbo pump while the temperature Tc and Tw are kept constant. It is obvious that changing the pressure in the reactor modify both the flux and the molecule resident time in the hot region.

A gas ramp allows a controlled flux of oxygen in the reactor.

From the reactor the wafer can be transported on a magnetic rod to the manipulator in the analysis chamber. This UHV chamber is equipped with an Auger spectrometer and thermal annealing capabilities. Post thermal processing up to $650^{\circ} \mathrm{C}$ can be done under UHV conditions. The chemical surface composition can be deduced from the energy distribution of Auger electrons emitted by the $2 \mathrm{keV}$ electron irradiated surface. We must keep in mind that Auger spectroscopy is very sensitive to the surface. The probed depth is less than $3 \mathrm{~nm}$ for electrons around $100 \mathrm{eV}$ due to the limited free path of electrons in matter.

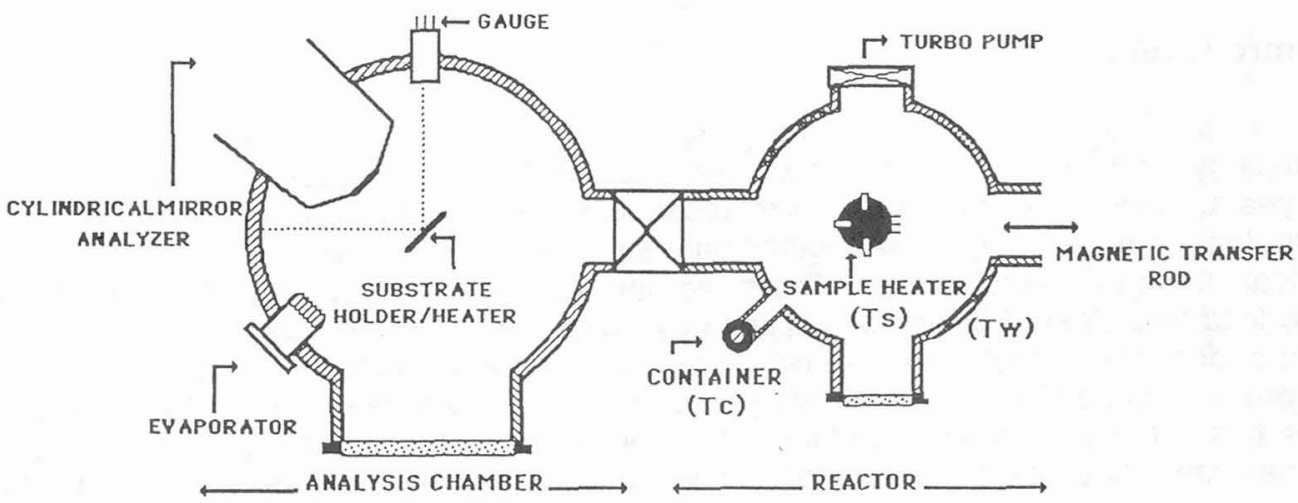

Figure 1: Experimental Set.up. 


\section{3) Experimental process:}

All the substrates investigated are based on silicon (111) or (100). Before processing the one inch wafers are pretreated to obtain a clean and defect free surface.

The silicon substrate is loaded after HF buffer etch dip and without being rinsed. This procedure is known to strip the silicon oxide and leaves a clean silicon surface. This surface is hydrogen saturated and passivated (ref.15). This is confirmed by the Auger spectra of figure $\mathrm{n}^{\circ} 2$ corresponding to the as introduced surface (2a) and to a $600^{\circ} \mathrm{C}$ $10 \mathrm{~min}$. in situ annealing (2b). It shows the typical silicon LVV line at $92 \mathrm{eV}$ and no oxygen signature around $510 \mathrm{eV}$. The peak around $272 \mathrm{eV}$ is due to contamination by hydrocarbons which can be mostly desorbed by a short annealing $\left(15 \mathrm{~min}\right.$.) at $350^{\circ} \mathrm{C}$. We can assume that this cleaning procedure (HF dip and annealing) leads in our conditions to a silicon surface whith less than a monolayer of carbon and no oxygen.

The Polyphenylquinoxaline (PPQ) samples are obtained by spin coating on silicon (100) covered by an adhesion layer of CrN. Openings can be done through this insulator layer by local thermal decomposition induced by a $2.5 \mathrm{~nm}$ copper film. Copper deposited on PPQ through a microscope grid allows the design of a pattern: By annealing at $450^{\circ} \mathrm{C}$ during $1 \mathrm{~h}$ in oxygen the $1 \mu \mathrm{m}$ thick insulator film is only decomposed underneath the copper film (ref 16).

The results presented in this paper have been obtained by using the copper acetylacetonate as the precursor. The source of precursor is a pyrex container connected to the reactor which can be heated by a quartz lamp from ambient to $200^{\circ} \mathrm{C}$.
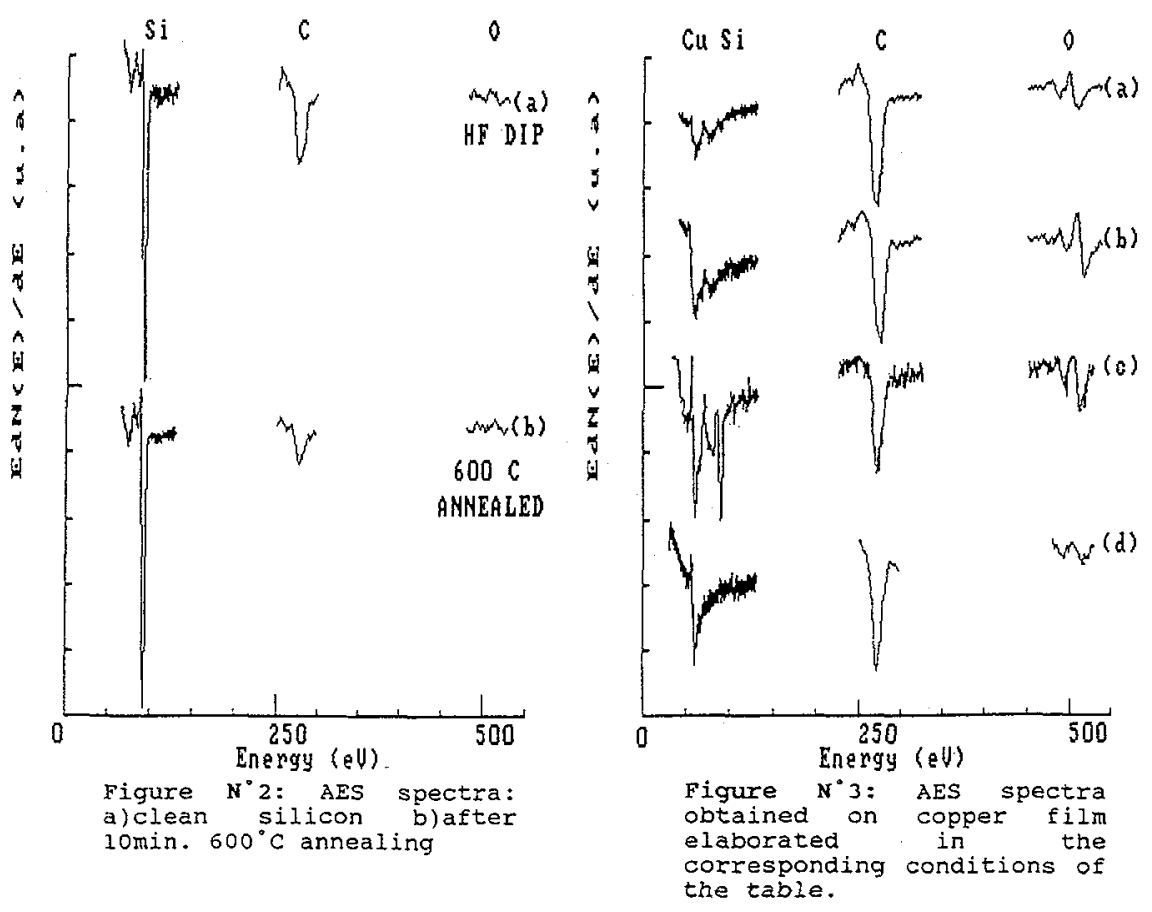


\section{4) Experimental results and discussion:}

We have tried different processing conditions and we will report those which gave the most interesting results. The investigated parameters were the substrate temperature, the wall temperature, the flux and contamination of the gas phase and the pressure. As a first result we notice that the leak level of the reactor is an important parameter and can influence the reproducibility of our results. Before beginning a process the pressure in the vessel is checked and must reach the low $10^{-5} \mathrm{~Pa}$ to be sure that no contamination by leaks could change the gas phase in the reactor. For clean silicon surface we observed that the growth rate in the absence of oxygen, is so low that such CVD process cannot be used for pratical applications. To obtain measurable growth rate a controlled amount of oxygen is needed in the gas phase.

The results presented below have been obtained on silicon (111) substrates using different processing conditions.

Our last results with $\mathrm{Si}(100)$ substrate are similar to those with $\mathrm{Si}(111)$. The corresponding Auger spectra are given on figure $n^{\circ} 3$ where the carbon peak to peak height has been normalized to the same value for each spectrum; a direct comparison can be done in these conditions. On this figure the label $(a, b, .$.$) correspond to the process$ $(a, b, c, .$.$) described in table 1$. All the substrate were cleaned before loading as described before. When the walls were intentionally over heated at $150^{\circ} \mathrm{C}$, the grown film is dominated by carbon. On the (3a) Auger spectrum only the $272 \mathrm{eV}$ peak is important no silicon is detected and a small contributions of copper and oxygen are detected at $58 \mathrm{eV}$ and $510 \mathrm{eV}$ respectively. This carbon film thickness is over the depth escape of electrons which means that the silicon is covered by at least more than $5 \mathrm{~nm}$ of carbon.

On sample (b) the typical copper Auger line is well pronounced around $58 \mathrm{eV}$ on spectrum 3b. As previously discussed the film thickness is over $5 \mathrm{~nm}$ since the silicon Auger line is not detectable. Carbon and oxygen are also well pronounced and remained

\begin{tabular}{|c|c|c|c|c|c|c|}
\hline RUN & SUBSTRATE & Tw $\left({ }^{\circ} \mathrm{C}\right)$ & To $\left({ }^{\circ} \mathrm{C}\right)$ & Ts $\left({ }^{\circ} \mathrm{C}\right)$ & Pressure (Torr) & $O_{2}$ Flow (sccm) \\
\hline (a) & Si<111> lype P & 150 & 120 & 325 & $1,00 E-01$ & 1.6 \\
\hline (b) & Si<111> type N & 150 & 120 & 350 & $1,00 \mathrm{E}-01$ & 1 \\
\hline (c) & Si<111> type N & 100 & 120 & 390 & $1,00 \mathrm{E}-01$ & 1 \\
\hline (d) & Si<111> lype P & 150 & 120 & 300 & $1,00 \mathrm{E}-01$ & 1.6 \\
\hline (e) & PPQ grids & 100 & 120 & 350 & $1,00 \mathrm{E}-01$ & 1 \\
\hline (f) & PPO + NCr & 100 & 120 & 350 & $1,00 \mathrm{E}-01$ & 1 \\
\hline
\end{tabular}

Table 1: Process conditions 
even after annealing at $350^{\circ} \mathrm{C}$. Annealings at higher temperature have not been investigated since copper is expected to induce complex reactions with silicon and oxygen leading to the formation of silicide. This contamination of the film by carbon is not due to the hydrocarbons produced by the reaction and readsorbed on the copper surface during cooling down in the reactor ambient. Hydrocarbons are expected to desorb at low temperature. Premilarly sputtering experiments on CVD copper film have shown that the carbon is mostly accumulated at the surface of the film. At the present time we have not determined the copper profile within the whole layer.

At higher substrate temperature $\left(T=390^{\circ} \mathrm{C}\right.$ ) (run c), the composition of the deposited film is quite different. Surface analysis gives the (3c) Auger spectrum where a silicon and a copper peaks are both detected at $92 \mathrm{eV}$ and $58 \mathrm{eV}$ respectively. This spectrum can easily be compared to the one obtained in the case of copper silicide (ref.17-18). It is well known that with evaporated layer copper react with clean silicon at temperature over $200^{\circ} \mathrm{C}$ to form metal rich silicide $\left(\mathrm{Cu}_{3} \mathrm{Si}, \mathrm{Cu}_{4} \mathrm{Si}\right)$. The peaks at $21.8^{\circ}$ and 25.35 on the diffraction patterns (figure $n^{\circ} 4 \mathrm{c}$ ) do not correspond to pure copper. They can be assign to a rich silicide compound. Both Auger spectroscopy and $X$-ray diffraction suggest the reaction of copper with silicon atoms. One can notice that carbon and oxygen are still observed in the film.

To obtain pure metallic films on silicon it is not possible to increase the temperature of deposition process since it induces the reaction of copper with the silicon underneath. Spectrum (3d) corresponds to a film grown at lower temperature $\left(300^{\circ} \mathrm{C}\right)$, but with a higher oxygen rate in the gas phase. It shows a typical Auger metallic copper peak at $58 \mathrm{eV}$. To
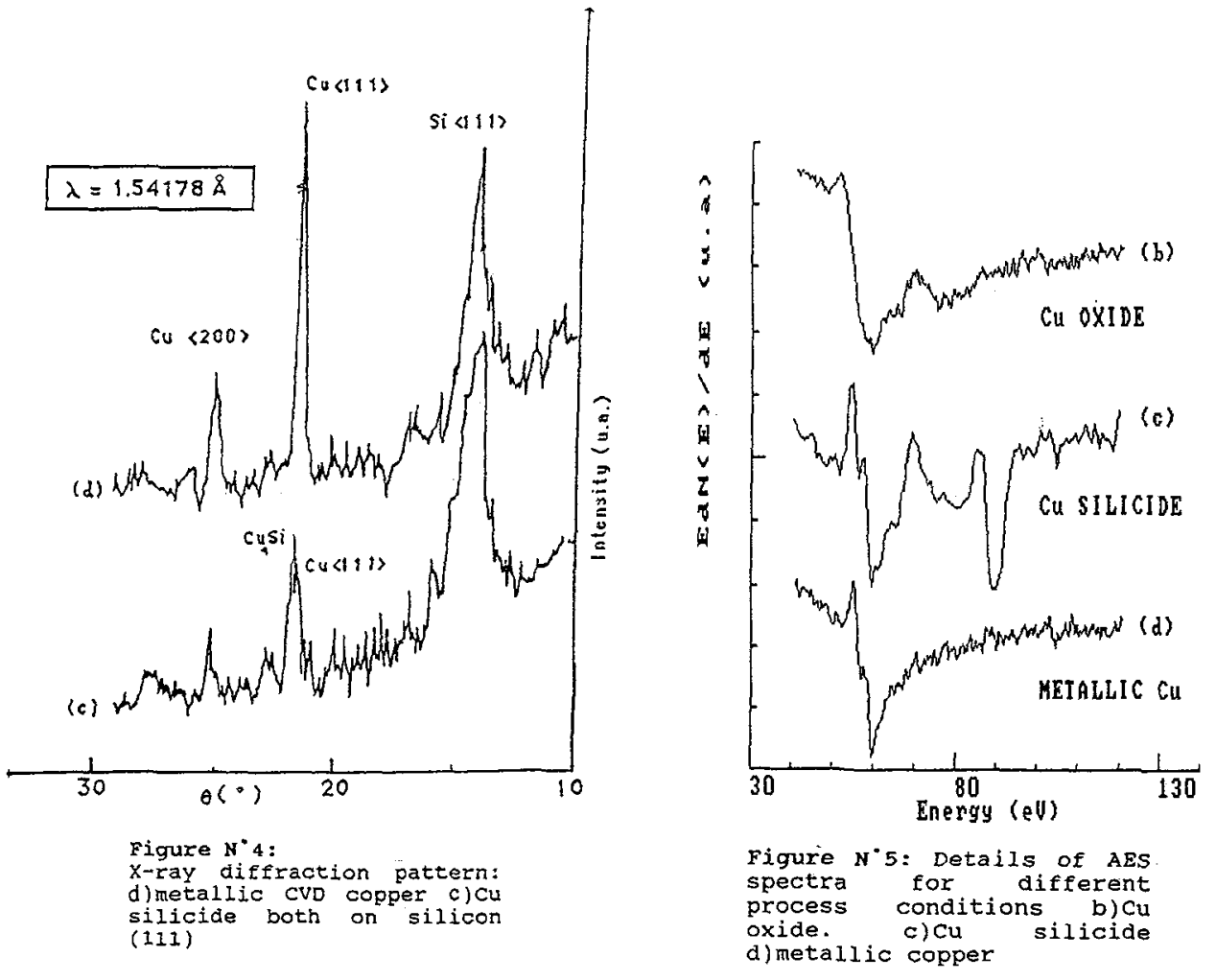
fully realize the differences between the previous cases this zone has been enlarged in figure $n^{\circ} 5$. On the (5b) spectrum the peak shape let think that the copper is in an oxidized state(ref.19). One can see that the $\mathrm{M}_{23} \mathrm{VV}$ Auger copper line at $58 \mathrm{eV}$ on the (5d) spectrum is split. The observation of this splitting is related to the metallic state of copper. The oxygen peak intensity is the lower of this series and confirm the metallic behavior of the film. X-ray diffraction gives an other proof of this point: the diffraction pattern (figure $n^{\circ} 4 d$ ) is similar to the one obtained on evaporated pure copper film. We emphasize the fact that in the case of a CVD copper film the reaction to form a silicide occurs at higher temperature that in the case of evaporated copper. This is an interesting point that needs to be clarified. A greater stability of the CVD copper film is important for devices fabrication. Copper is known to have a strong reaction with silicon and to diffuse very easily in it.

Concerning the selectivity of CU CVD, the SEM picture (fig $N^{\circ} 6$ ) has been obtained on a PPQ sample prepared as described above. The process conditions correspond to the $f$ run of table 1 . The sample temperature $350^{\circ} \mathrm{C}$ is compatible with the thermal stability of $P P Q$. This picture shows that the uncovered copper zone appears in dark while the bright one corresponds to the CVD copper film. It is clear from such picture that copper has been deposited selectively. By Xray-fluorescence microanalysis, the amount of copper is five time less in the dark area than in the bright area. The copper has been deposited selectively on the metallic surface. It does not seem that the predeposited $2.5 \mathrm{~nm}$ of copper influences the selectivity behavior. Other experiments where the PPQ has been removed by scribbing, lead in the same process conditions to a macroscopic copper film deposited only on the $\mathrm{CrN}$ layer. The mechanism that can explain the selectivity is certainly complex and further experiments need to be done to determine the sensitivity of the differential growth rate to the process parameters. It can be expected that the change of the process conditions can lead to a better selectivity.

Figure $\mathrm{N}^{\circ} 6$

SEM picture of selective CVD copper film. Dark area correspond to $\mathrm{PPQ}$ while bright area is the copper film.

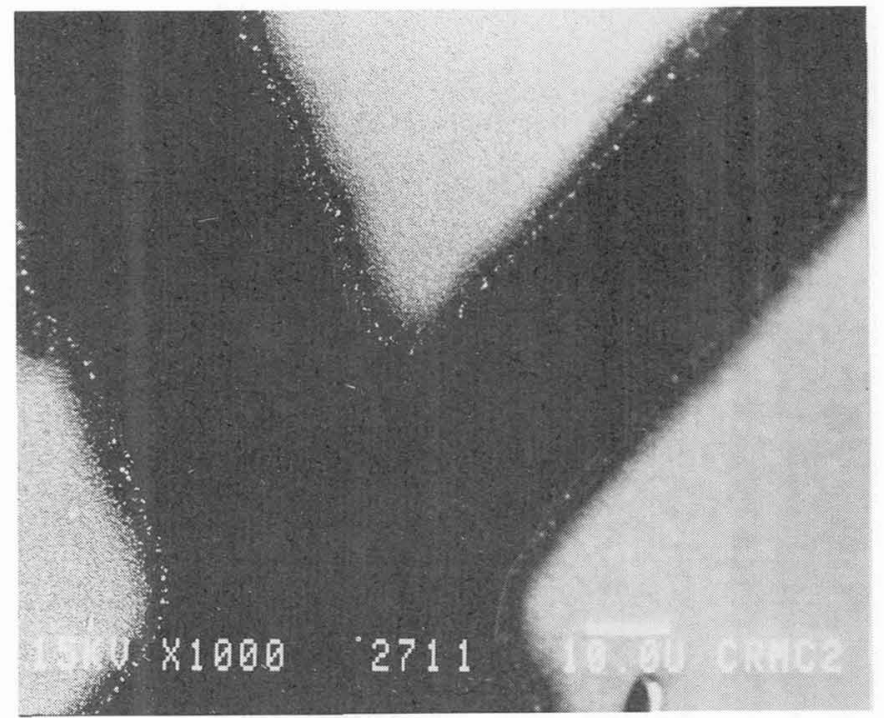




\section{6) Conclusion:}

From the study of the influence of the process conditions, we have determined CVD processes allowing a control of the chemical composition of the film deposited on silicon. Metallic copper films are formed at a temperature $\left(300^{\circ} \mathrm{C}\right)$ compatible with processing silicon devices. The formation of CVD copper silicide occurs at higher temperature than in the case of evaporated copper. Further experiments need to be done to understand the increase in the stability of the $\mathrm{Cu} / \mathrm{Si}$ interface. Oxygen and carbon could induce this peculiar behavior of copper in CVD films. An interesting result is the selectivity obtained on a real microelectronic interconnection problem where one needs to deposit a copper film in openings through PPQ. The growth rate differences could be explained by a change in the interaction of species with the surface.

The authors thanks S.Nitsche for the scanning electron analysis. We also had fruitful discusion with Dr. M.Liehr for the understanding of MOCVD reactions.

\section{REFERENCES}

/1/ Hemert-R-L Spendlove-L-B Sievers-R-E J.Electrochem.Soc. 112 (1965) 1123

/2/ Williams-J-O Angew.Chem.Int.Ed.Engl. Adv.mater 28 (1989) 1110

/3/ Houle-F-A Appl.Phys. A 41 (1986) 315

/4/ Oehr-C Suhr-H Appl.Phys. A 45 (1988) 151

15/ Ishihara-K Yamazaki-K Hamada-H Kamisako-K Tarui-Y

Japan J.Appl.Phys. 292103 (1990) 2103

/6/Beach-DB Legoues-FK Hu-CK Chem. Mater. 2 (1990) 217

17/ Suhr-H Etspnler-A Feurer-E Oehr-C Plasma Chem. and Plasma Proc. 8 (1988) 1

18/ Houle-F-A Jones-C-R Baum-T Pico-C Kovac-C-A Appl.Phys.Lett. 461985204

19/ Hazuki-Y, Yano-H, Horioka, Hayasaka-N, Okano-H Dry Process Simposium (1989)

/10/ Jones-G-W Tandom-S J.Electr.Material 19 (1989) 89

111/ Madar-R Bernard-C J. de Phys. Colloque C5 (1989) 50

112/ Hsieh-T-Y Chun-H-G Kwong-D-L Appl.Phys.Lett. 55 (1989) 2408

113/ Sasaoko-C Mori-K Kato-Y Usui-A Appl.Phys.Lett. 55 (1989) 741

/14/ Horiike-Y Ichihara-T Sakaue-H Appl.Surf.Sc. 46 (1990) 168

/15/ Grunthaner-P-J Fathauer-RW Grunthaner-FJ Lin-TL Liu-J Pate-B J

Electrochem. Soc. 134 (1987) 545

116/ Even-R Palleau-J Oberlin-J-C Pantel-R Laviale-D Templier-F Torres-J Giustiniani-R Cros-A Nechtschein-J to be published in proceedings of STEPI Montpellier June 1991

/17/ Mathiez-P Daugy-E Salvan-F Métois-J-J Hanbucken-M Surf.Sci. 168 (1886) 546

/18/ Aboelfotoh-M-O Cros-A Svenson-B-G Tu-K-N Phys.Rev. 41 (1990) 9819

/19/ Benndorf-C Egert-B Keller-G Tieme-F Surf.Sci.Z4 (1978) 216 